\title{
An Arabinogalactan-protein from Rape Leaves
}

\author{
Kiyoshi Ogura, Yoichi Tsumuraya, Yohichi Hashimoto \\ and Shigeru YAMAMOTO* \\ Department of Biochemistry, Faculty of Science, Saitama University, \\ 255 Shimo-okubo, Urawa 338, Japan \\ * Laboratory of Serology and Biochemistry, \\ National Research Institute of Police Science, \\ 6 Sanban-cho, Chiyoda-ku, Tokyo 102, Japan
}

Received January 23, 1985

\begin{abstract}
A L-fucose-containing arabinogalactan-protein that strongly inhibited hemagglutination by eel anti-H agglutinin of human $\mathrm{O}$ erythrocytes was purified from hot phosphate-buffered saline extracts of mature leaves of rape, Brassica campestris. The purified glycoconjugate consisted of $90 \%$ of the polysaccharide moiety comprising L-fucose, L-arabinose, D-galactose, 4- $O$-methyl-Dglucuronic acid, and D-glucuronic acid, and $4 \%$ of the hydroxyproline-rich protein portion. Upon methylation, periodate oxidation, and enzymatic degradation, we found that consecutive $\beta-(1 \rightarrow 3)$ linked D-galactopyranosyl residues constituted a backbone chain of the polysaccharide moiety, to which the side chains of $\beta$-( $1 \rightarrow 6)$-linked D-galactopyranosyl residues were attached through O-6. Most of L-arabinofuranosyl residues were linked as single units through O-3 to the side chains while a small quantity of the sugar was present as $(1 \rightarrow 2)-,(1 \rightarrow 3)$-, or $(1 \rightarrow 5)$-linked inter-chain residues. Single residues of $\alpha$-L-fucopyranose, apparently attached to $(1 \rightarrow 2)$-linked L-arabinofuranosyl residues, reacted with eel anti-H precipitin and Aleuria aurantia L-fucose-specific lectin, and were assumed to be crucial in the expression of the $\mathrm{H}$-like activity. The uronosyl residues were also located at the non-reducing terminal ends. Reductive alkaline degradation of the arabinogalactanprotein provided indications that the polysaccharide chains were mainly conjugated through serine$O$-glycosidic linkages to the polypeptide core. In an immunoprecipitation test, the rape leaf arabinogalactan-protein cross-reacted with antisera raised against radish leaf arabinogalactanprotein, indicating that these cruciferous arabinogalactan-proteins share common immunodeterminant(s) in their molecules.
\end{abstract}

The occurrence of blood group $\mathrm{H}$-active substances in the plant kingdom has first been reported by Springer et al., who found the serological activity in complex polysaccharides isolated from aqueous extracts of twigs of Taxus cuspidata and Sassafras albidum, and demonstrated that 2-O-methyl-L-fucose and 3$O$-methyl-D-galactose acted as the immunodeterminants, respectively. ${ }^{1,2)}$ In our previous work on $\mathrm{H}$-like substances in leaf tissues of cruciferous plants, we have characterized several L-fucose-containing arabinogalactanproteins (AGPs) that strongly inhibit on the agglutination of human $\mathrm{O}$ erythrocytes with eel anti-H agglutinin. ${ }^{3}$ Subsequent structural investigations of radish leaf AGPs provided evidence that their polysaccharide moieties could be regarded as a typical arabino-3,6galactan having $\alpha$-L-fucopyranosyl- $(1 \rightarrow 2)-\alpha-L-$ arabinofuranosyl-( $1 \rightarrow$, as a possible immunodeterminants group for their H-like activity. ${ }^{4.5)}$ This paper is concerned with structural features and serological properties of a rape leaf AGP in comparison with those of radish leaf AGPs.

\section{EXPERIMENTAL}

Materials. An AGP with $\mathrm{H}$-like activity was isolated from hot phosphate-buffered saline (PBS, $0.0145 \mathrm{M}$ phosphate buffer, $\mathrm{pH} 7.2$, containing $0.13 \mathrm{M} \mathrm{NaCl}$ ) extracts of mature leaves of the rape, Brassica campestris L. subsp. Napus Hook. ${ }^{3)}$ An $\alpha$-L-arabinofuranosidase purified from the culture filtrate of Rhodotorula flava $^{6}$ ) was provided by Dr. N. Shibuya, National Food Research Institute, 
Tsukuba, Ibaraki, Japan. A partially purified preparation of a $\beta$-galactanase was prepared from Driselase, a commercial cellulase product as previously described. ${ }^{4)} \mathrm{A}_{\mathrm{L}-}$ fucose-specific lectin of orange peel fungus, Aleuria aurantia,${ }^{7)}$ was a generous gift of Dr. N. Kochibe, Gunma University, Gunma, Japan.

Analytical methods. The contents of total sugar, reducing sugar, uronic acid, and protein were measured colorimetrically. ${ }^{3.4)}$ Qualitative analysis of sugars was done by paper chromatography (PC) on Whatman No. 1 and $3 \mathrm{MM}$ papers in a solvent system of 1-butanol-pyridinewater $(6: 4: 3, \mathrm{v} / \mathrm{v} / \mathrm{v})$. The spots of sugars on paper chromatograms were detected by alkaline silver nitrate or $p$-anisidine hydrochloride reagent. For the detection of non-reducing sugars, the paper after the run was sprayed with $1 \% \mathrm{NaIO}_{4}$ in $50 \%$ aqueous acetone before silver nitrate treatment. Analysis of sugars by gas liquid chromatography (GLC) was done in a Shimadzu GC-5A gas chromatograph with a flame ionization detector. Monosaccharides and their partially methylated derivatives were converted to their corresponding alditol acetates and separated isothermally on a glass column ( $3 \mathrm{~mm} \times 2 \mathrm{~m}$ ) of $3 \%$ ECNSS-M on Gas Chrom Q at $180^{\circ} \mathrm{C}$ or $190^{\circ} \mathrm{C}$, and on a glass capillary column $(0.28 \mathrm{~mm} \times 50 \mathrm{~m})$ of $\mathrm{G}-\mathrm{SCOT}$ with Silar-10C at $180^{\circ} \mathrm{C}$. The samples $(1 \sim 2 \mathrm{mg})$ of the rape leaf AGP and its degradation products were hydrolyzed with $\mathrm{M} \mathrm{H}_{2} \mathrm{SO}_{4}$ $(0.6 \mathrm{ml})$ for $4 \mathrm{hr}$ at $100^{\circ} \mathrm{C}$. After neutralization $\left(\mathrm{BaCO}_{3}\right)$ and centrifugation, the hydrolyzates were deionized with a short column of Dowex 50W $\left(\mathrm{H}^{+}\right)$and analyzed by $\mathrm{PC}$ or GLC.

Methylation analysis. Samples $(1 \sim 5 \mathrm{mg})$ of the rape AGP and its modified or degraded products were methylated in dimethylsulfoxide $(2 \mathrm{ml})$ with methylsulfinyl anion and methyl iodide. ${ }^{8)}$ The methylated polysaccharides were suspended in $72 \% \mathrm{H}_{2} \mathrm{SO}_{4}(0.1 \mathrm{ml})$, left for $1 \mathrm{hr}$ at $4{ }^{\circ} \mathrm{C}$, then diluted with water $(0.8 \mathrm{ml})$, and hydrolyzed by heating for $4 \mathrm{hr}$ at $100^{\circ} \mathrm{C}$. Hydrolysis of the permethylated oligosaccharides was made with $2 \mathrm{M}$ trifluoroacetic acid $(0.6 \mathrm{ml})$ for $4 \mathrm{hr}$ at $100^{\circ} \mathrm{C}$.

Periodate oxidation. The AGP $(50 \mathrm{mg})$ was dissolved in $0.05 \mathrm{M} \mathrm{NaIO}_{4}(50 \mathrm{ml})$ and left to react at $4^{\circ} \mathrm{C}$ in the dark. When the oxidation was completed after $96 \mathrm{hr}$, the formic acid produced and periodate consumed were 0.18 and $0.83 \mathrm{~mol}$ per sugar residue, respectively. Excess periodate was decomposed by adding 1,2-ethanediol $(2 \mathrm{ml})$ and the mixture was dialyzed against water. Reduction with $\mathrm{NaBH}_{4}$ of the oxidized product gave the corresponding glycan-polyalcohol $(30.1 \mathrm{mg})$, which was used for Smith degradation $^{9)}$ with $\mathrm{M}$ trifluoroacetic acid $(4 \mathrm{ml})$. After standing for $48 \mathrm{hr}$ at $25^{\circ} \mathrm{C}$, the resulting products were fractionated with $75 \%$ methanol yielding a polymer $(7.2 \mathrm{mg})$ and methanol-soluble sugar fraction $(19.1 \mathrm{mg})$ containing $27 \%$ of total sugar. From the low-molecular- weight fraction, oligosaccharides were separated by chromatography on a column of Dowex 1 (formate) followed by preparative PC. Three components having $R_{G l c}$ of 0.80 , 0.22 , and 0.03 were obtained with the respective yields of $2.2,0.7$, and $0.3 \mathrm{mg}$.

Carboxyl-reduction. The carboxyl groups of uronic acid residues in the AGP $(10 \mathrm{mg})$ were reduced by the method of Taylor and Conrad, ${ }^{10)}$ involving reaction with 1-ethyl3-(3-dimethylaminopropyl)carbodiimide and then reduction with $\mathrm{NaBH}_{4}$.

Enzymatic degradation. The AGP (30 mg) was incubated under toluene with $R$. flava $\alpha$-L-arabinofuranosidase ( 6 units) in $0.01 \mathrm{M}$ citrate-phosphate buffer, $\mathrm{pH} 3.0(4 \mathrm{ml})$ at $37^{\circ} \mathrm{C}$. After incubation for $10 \mathrm{hr}$, additional enzyme $(3$ units) was added to the reaction mixture which was left standing for 20 more hours. When liberation of reducing sugars $(25.9 \%$ as L-arabinose) reached a constant, the reaction was ended by heating in a boiling water bath for $5 \mathrm{~min}$ and then the mixture was cooled. The digest was deionized with Dowex $50 \mathrm{~W}\left(\mathrm{H}^{+}\right)$and filtered on a column $(3 \times 80 \mathrm{~cm})$ of Sephadex G-75 gel. Elution with water from the column made it possible to separate a polymer $(21 \mathrm{mg})$ from the L-arabinose released. A portion $(10 \mathrm{mg})$ of the polymer was then degraded with $\beta$-galactanase $(0.1 \mathrm{mg})$ in $0.05 \mathrm{M}$ acetate buffer, $\mathrm{pH} 4.0(4 \mathrm{ml})$ for $24 \mathrm{hr}$ at $37^{\circ} \mathrm{C}$ under toluene. After heat-inactivation of the enzyme, the digest (apparent conversion to D-galactose, 16.3\%) was separated on a column of Sephadex G-75 into three sugar fractions, designated I $(2.5 \mathrm{mg})$, II $(2.3 \mathrm{mg})$, and III $(5.3 \mathrm{mg})$, which were collected in accordance with their respective partition coefficient $K_{a v}\left(\left(V_{e}-V_{o}\right) /\left(V_{t}-V_{o}\right)\right)$ ranges of $0 \sim 0.2,0.3 \sim 0.65$, and $0.75 \sim 1.0$.

Reductive alkaline degradation. The AGP $(9 \mathrm{mg})$ was dissolved in $0.5 \mathrm{M} \mathrm{NaOH}(1 \mathrm{ml})$ containing $0.5 \mathrm{M} \mathrm{NaBH}_{4}$ and incubated for $24 \mathrm{hr}$ at $25^{\circ} \mathrm{C}$. The reaction mixture was then treated successively with $\mathrm{PdCl}_{2}-\mathrm{HCl}$ and alkaline borohydride by the method of Downs et al., ${ }^{11}$ and deionized by using a column $(2 \times 28 \mathrm{~cm})$ of Sephadex G15. The product thus obtained was hydrolyzed for the analysis of amino acid composition. ${ }^{3)}$ Another sample obtained from the AGP $(1.5 \mathrm{mg})$ by reductive alkaline treatment was neutralized with $6 \mathrm{M}$ acetic acid, evaporated to dryness, and dissolved in water $(1 \mathrm{ml})$. The change in the molecular size of the AGP was examined on a Sepharose CL-6B column $(1 \times 85 \mathrm{~cm})$ by following the elution profiles of sugar and protein.

Serological method. The hemagglutination-inhibiting activity of the AGP and its chemically and enzymatically modified products was assayed by using serial 2-fold dilutions $(25 \mu \mathrm{l})$ of the samples in PBS or $0.85 \% \mathrm{NaCl}$ (saline) plus $25 \mu \mathrm{l}$ of eel anti-H agglutinin or L-fucosespecific lectin (titer $1: 8$ ). The activity was measured by the addition of human $\mathrm{O}$ erythrocytes in saline and expressed 
as the minimum concentration $(\mu \mathrm{g} / \mathrm{ml})$ or as the reciprocal values of the lowest dilution $\left(2^{n}\right)$ causing complete inhibition of hemagglutination. The precipitation reactions of the samples against eel anti-H precipitin, rabbit antiradish leaf AGP sera, ${ }^{5)}$ and $A$. aurantia $\mathrm{L}$-fucose-specific lectin were examined by the Ouchterlony double diffusion method $^{12)}$ on a $1.5 \%$ Difco agar plate containing $0.025 \mathrm{M}$ barbital buffer, $\mathrm{pH} 8.4$, or PBS in the presence of $0.01 \%$ trypan blue. The diffusion was allowed to occur in moist atmosphere for $24 \mathrm{hr}$ at room temperature.

\section{RESULTS AND DISCUSSION}

From hot PBS-extracts of mature rape leaves, an AGP having blood group H-like activity was purified by ethanol precipitation followed by successive chromatographic fractionations using columns of DEAE-cellulose and Sepharose 6B. ${ }^{3)}$ The apparent homogeneity of the purified AGP was verified by high voltage electrophoresis and ultracentrifugal analysis. The rape leaf AGP having an apparent molecular weight of 50,000 was composed of a large part $(90.3 \%$ ) of a polysaccharide moiety associated with a small quantity $(3.8 \%)$ of hydroxyproline-rich protein. ${ }^{3)}$ Upon examination of the monosaccharide components by PC and GLC on a silar-10C column, one of the carboxyl-reduced products was confirmed to be 4-O-methyl-D-glucose since the $R_{G l c}(1.54)$ and $T_{G l c}(0.87)$ of the derivative were in good agreement with those of the authentic specimen. ${ }^{3)}$ The monosaccharide composition of the carboxyl-reduced AGP revealed that the native AGP consisted of L-fucose, L-arabinose, D-galactose, 4- $\mathrm{O}$ methyl-D-glucuronic acid, and D-glucuronic acid in molar proportions of 4.3:37.0: $53.7: 3.8: 1.2$. Upon testing for hemagglutination inhibition, this L-fucose-containing glycoconjugate was shown to completely inhibit the hemagglutination of human $\mathrm{O}$ erythrocytes by eel anti-H agglutinin at concentration of $10 \mu \mathrm{g} / \mathrm{ml}^{3}{ }^{3)}$

Results of methylation analysis of the native AGP are summarized in Table I (column A), that revealed high molar proportions of 2,4,6tri-, 2,3,4-tri-, and 2,4-di- $O$-methyl-D-galactose, indicating that the polysaccharide moiety is a typical arabino-3,6-galactan. ${ }^{13)}$ A preponderance of 2,3,5-tri- $O$-methyl-L-arabinose, together with small amounts of 3,5-, 2,5-, and 2,3-di- $O$-methyl-L-arabinose could be taken as indications that a majority of the $\mathrm{L}-$ arabinofuranosyl residues were located at the non-reducing terminal end while some of the

Table I. Methylation Analyses of Native AGP and Its Modified or Degraded Products

\begin{tabular}{|c|c|c|c|c|c|c|c|c|}
\hline \multirow{2}{*}{ Sugar component ${ }^{a}$} & \multirow{2}{*}{ Mode of linkage } & \multirow{2}{*}{$\mathrm{T}^{b}$} & \multicolumn{6}{|c|}{ Molar percent } \\
\hline & & & A & $\mathrm{B}$ & $\mathrm{C}$ & $\mathrm{D}$ & $\mathrm{E}$ & $\mathrm{F}$ \\
\hline 2,3,5- $\mathrm{Me}_{3}-\mathrm{L}-\mathrm{Ara}$ & L-Ara $f-(1 \rightarrow$ & 0.55 & 23.1 & 17.9 & 7.0 & 1.0 & $-^{c}$ & - \\
\hline $2,3,4-\mathrm{Me}_{3}-\mathrm{L}-\mathrm{Fuc}$ & L-Fuc $p-(1 \rightarrow$ & 0.67 & 4.0 & 2.9 & - & 5.1 & 18.1 & 11.2 \\
\hline 3,5-Me $-\mathrm{M}-\mathrm{Ara}$ & $\rightarrow 2)$-L-Ara $f-(1 \rightarrow$ & 0.93 & 5.3 & 5.9 & - & 6.7 & 11.5 & 19.8 \\
\hline $2,3,4,6-\mathrm{Me}_{4}-\mathrm{D}-\mathrm{Glc}$ & D-Glc $p-(1 \rightarrow$ & 1.00 & - & 4.8 & - & - & - & - \\
\hline $2,5-\mathrm{Me}_{2}-\mathrm{L}-\mathrm{Ara}$ & $\rightarrow 3)$-L-Araf-( $1 \rightarrow$ & 1.09 & 1.0 & 0.9 & - & - & - & - \\
\hline $2,3,4,6-\mathrm{Me}_{4}-\mathrm{D}-\mathrm{Gal}$ & D-Galp- $(1 \rightarrow$ & 1.21 & 4.1 & 3.5 & 16.9 & 9.5 & 25.9 & 4.7 \\
\hline $2,3-\mathrm{Me}_{2}-\mathrm{L}-\mathrm{Ara}$ & $\rightarrow 5)-\mathrm{L}-\operatorname{Ara} f-(1 \rightarrow$ & 1.31 & 6.8 & 6.9 & - & - & - & - \\
\hline $2,4,6-\mathrm{Me}_{3}-\mathrm{D}-\mathrm{Gal}$ & $\rightarrow 3)$-D-Galp-(1 $\rightarrow$ & 2.04 & 12.9 & 9.4 & 21.8 & 9.8 & - & 2.0 \\
\hline $2,3,4-\mathrm{Me}_{3}-\mathrm{D}-\mathrm{Gal}$ & $\rightarrow 6)-\mathrm{D}-\mathrm{Gal} p-(1 \rightarrow$ & 3.17 & 10.9 & 12.3 & 32.4 & 26.0 & 35.8 & 46.8 \\
\hline $2,4-\mathrm{Me}_{2}-\mathrm{D}-\mathrm{Gal}$ & $\rightarrow 3,6)-\mathrm{D}-\mathrm{Gal} p-(1 \rightarrow$ & 5.40 & 31.9 & 35.5 & 21.9 & 16.0 & 8.7 & 15.5 \\
\hline Free L-Arabinose ${ }^{d}$ & & & & & & 25.9 & & \\
\hline
\end{tabular}

a 2,3,5-Me $\mathrm{M}_{3}$-L-Ara =1,4-di- $O$-acetyl-2,3,5-tri- $O$-methyl-L-arabinitol, etc.

${ }^{b}$ Retention time relative to $2,3,4,6-\mathrm{Me}_{4}-\mathrm{D}-\mathrm{Glc}$ on a Silar-10C column.

c Not detectable.

${ }^{d}$ Reducing sugar in an $\alpha$-L-arabinofuranosidase-digest of the AGP.

A, native AGP; B, carboxyl-reduced AGP; C, a polymer resistant to Smith degradation; D, an $\alpha$-Larabinofuranosidase-digested product; E, Fraction I (a $\beta$-galactanase-digested product) and F, Fraction II (a $\beta$ galactanase-digested product). 
sugar were present as internal furanosyl residues substituted at $\mathrm{O}-2, \mathrm{O}-3$, or O-5 positions. Detection of 2,3,4-tri- $O$-methyl-Lfucose as a sole methylated derivative of $\mathrm{L}$ fucose indicated that this sugar originated exclusively from the non-reducing terminal groups. As shown in Table I (column B), an appearance of 2,3,4,6-tetra- $O$-methyl-Dglucose among the methylated sugars after carboxyl-reduction of the AGP is coincident with the location of the uronosyl residues at the non-reducing terminal ends of the native AGP.

Smith degradation of the AGP resulted in a nearly complete elimination of the sugar residues located at primary and secondary side chains of the polysaccharide moiety, giving rise to a polymer and low-molecular-weight degradation products. The polymer apparently representing a core structure of the rape AGP had $[\alpha]_{D}^{20}-27^{\circ} \quad(c=0.5$, water $)$ and gave a single peak corresponding to an approximate molecular weight of 30,000 , as estimated by gel permeation chromatography on a Sepharose CL-6B column. As regards its monosaccharide composition, D-galactose was predominant with a small quantity of L-arabinose (molar percent, 93: 7). Data in Table I (column C) for methylation analysis implied that the Smith degradation product was a branched Dgalactan carrying single units of Larabinofuranosyl residues as the non-reducing terminal sugars. On the other hand, the lowmolecular-weight fraction contained a large amount of glycerol and neutral non-reducing oligosaccharides, which were further resolved by preparative PC into three components. Their $R_{G l c}$ values coincided with a series of $\beta$ $(1 \rightarrow 6)$-linked D-galacto-oligosaccharides having glycerol at the reducing end, obtained after Smith degradation of radish leaf AGPs. ${ }^{4}$ Methylation analysis of these component showed the presence of 2,3,4,6-tetra- and 2,3,4-tri- $O$-methyl-D-galactose in the molar proportions of $100,45: 55$, and $34: 66$ in the order of their decreasing mobilities on PC. From the above data, these components were $\beta$-D-Galp-( $1 \rightarrow 1)$-D-glycerol, $\beta$-D-Galp- $(1 \rightarrow 6)$ -

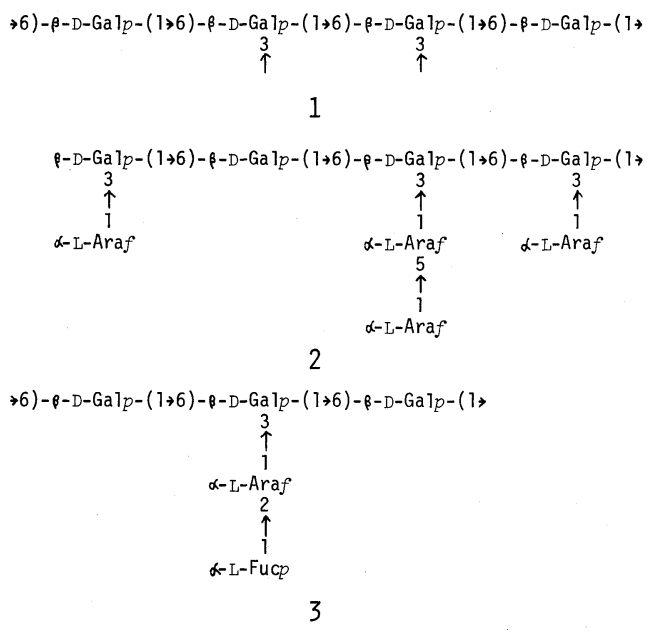

$\beta$-D-Galp-(1 $\rightarrow 1)$-D-glycerol, and $\beta$-D-Gal $p$ $(1 \rightarrow 6)-\beta$-D-Gal $p-(1 \rightarrow 6)-\beta$-D-Gal $p-(1 \rightarrow 1)$-Dglycerol, respectively. Consistent with the principle of Smith degradation, it can be deduced that these serial oligosaccharides might have arisen from consecutive $\beta-(1 \rightarrow 6)$ linked D-galactosyl residues substituted at O-3 with periodate-oxidizable sugar residues, with such a sugar sequence being flanked by unsubstituted $\quad \beta$-(1 $\rightarrow 6)$-linked D-galactosyl residues (1). These structure might represent a typical side chain struture of the native AGP.

Upon digestion with $\alpha$-L-arabinofuranosidase, liberation of a large amount of Larabinose occurred from the AGP, leaving an enzyme-modified polymer. The degraded polymer was recovered by gel permeation chromatography on a Sephadex G-75 column, and was found to consist of L-fucose, L-arabinose, and D-galactose (molar percent, $7: 13: 80$ ), together with uronic acid. Data of the methylation analysis of the enzymemodified product compared with that of the native AGP in Table I (columns D and A) confirmed that the enzyme treatment was highly effective for the removal of $(1 \rightarrow 3)$-, $(1 \rightarrow 5)$-, or non-reducing terminal L-arabinosyl residues, resulting in a concomitant increase in molar proportions of non-reducing terminal and $(1 \rightarrow 6)$-linked D-galactosyl residues. In contrast, molar proportions of non-reducing 
terminal L-fucosyl and $(1 \rightarrow 2)$-linked Larabinosyl residues remained unaffected even after the enzymatic degradation. These results led to the assumption that L-arabinofuranosyl residues in the native AGP might be attached through O-3 to the terminal or the interchain $\beta$ - $(1 \rightarrow 6)$-linked D-galactosyl residues of the side chains (2). For further structural analysis, $\beta$-galactanase was used effectively to degrade the $\alpha$-L-arabinofuranosidasetreated AGP. After prolonged digestion, the resultant products were separated on a Sephadex G-75 column into three fractions depending on their respective $K_{a r}$ ranges. Fraction III consisted of $\mathrm{L}$-fucose, $\mathrm{L}$-arabinose, and D-galactose (molar ratio, $0.03: 0.04: 1.0$ ), and uronic acid. Analysis by PC of this fraction revealed that the major constituents were D-galactose and two galacto-oligosaccharides having $R_{G l c}$ values $(0.20$ and 0.04$)$ corresponding to those of $\beta$-D-Galp-( $1 \rightarrow 6)$-D-Gal $p$ and $\beta$ D-Galp-(1 $\rightarrow 6)-\beta$-D-Galp-( $1 \rightarrow 6)-\mathrm{D}-\mathrm{Gal} p$, which were obtained from radish leaf AGP. ${ }^{4)}$ Upon acid hydrolysis, fraction II gave L-fucose, Larabinose, and D-galactose (molar ratio, $0.15: 0.23: 1.0)$. Structural analysis of the oligosaccharides on the whole by methylation (Table I, column F) indicates a high content of $(1 \rightarrow 6)$-linked D-galactosyl residues substituted at O-3 with L-fucosyl or L-arabinosyl residues. These oligosaccharides could be fragments of intermediate size liberated from the side chains of rape leaf AGP by the action of $\beta$-galactanase. The high-molecular-weight fraction I had a monosaccharide composition of $\mathrm{L}$ fucose, L-arabinose, and D-galactose (molar ratio, $0.26: 0.38: 1.0$ ), and uronic acid. It is noteworthy that this fraction appears to retain a large part of the protein portion since it contains a higher proportion of protein $(9 \%)$ than those of the native AGP $(3.8 \%)$ and $\alpha$-Larabinofuranosidase-treated AGP $(4.9 \%)$. In view of methylation analyses of these large fragments (Table I, columns E and F), it is highly probable that a common feature of their structure is a disaccharide unit of an equimolar proportion of non-reducing terminal Lfucopyranosyl and $(1 \rightarrow 2)$-linked L-arabino-
Table II. Changes in Serine, Threonine, and Alanine Contents in the AGP Before and after Reductive Alkali Treatment

\begin{tabular}{lrrr}
\hline \multicolumn{1}{r}{ Amino acid } & Before & After & $(\%)$ \\
\hline Hydroxyproline & 120.8 & 128.5 & +6.4 \\
Serine & 58.1 & 45.8 & -21.2 \\
Threonine & 40.5 & 38.0 & -6.2 \\
Alanine & 45.8 & 53.8 & +17.5 \\
\hline
\end{tabular}

The residues of amino acids are given in $\mu \mathrm{mol} / \mathrm{g}$ of the AGP.

furanosyl residues. This unit might be attached at O-3 to D-galactosyl residues of the side chains (3).

Reductive alkaline degradation of the AGP was done in $0.5 \mathrm{M} \mathrm{NaOH}$ containing $0.5 \mathrm{M}$ $\mathrm{NaBH}_{4}$ to analyze carbohydrate-protein linkages susceptible to alkaline $\beta$-elimination reaction. An elution profile of the products by gel permeation chromatography showed a large reduction in the molecular weight of the native AGP and its conversion to a polydisperse form, possibly as a result of cleavage in alkali-labile carbohydrate-protein linkages. In Table II are summarized the results of amino acid analysis that showed a decrease in serine content with an increase in conversion to alanine as a reduced $\beta$-elimination product of serine, although their stoichiometric recovery could not be obtained. Thus, this finding suggested that the polysaccharide chains of rape leaf AGP are linked through $O$-glycosidic linkage to serine residues in the polypeptide portion.

In a double diffusion test, rape leaft AGP reacted with eel anti-H precipitin to form a single precipitin line that fused completely with those of L-fucose-containing AGPs, purified from the leaves of radish or turnip. ${ }^{3)}$ This indicates that these cruciferous AGPs share a common serologically active structure involving L-fucosyl residues. Of the chemically and enzymatically modified AGPs tested, the carboxyl-reduced and $\alpha$-L-arabinofuranosidase-treated rape leaf AGP maintained the serological response, apparently due to the presence of intact L-fucosyl residues. 


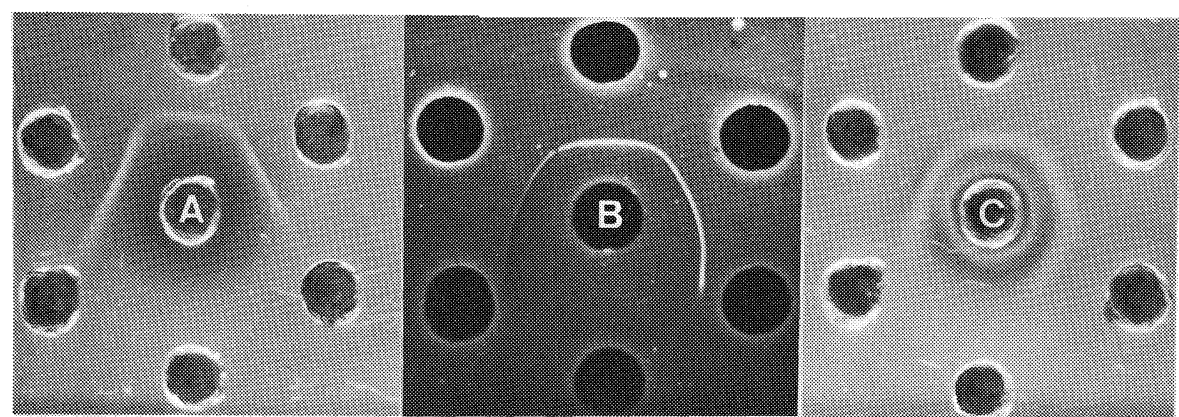

FIG. 1. Immunodiffusion Patterns Showing the Reactions of the Native AGP and Its Modified Products against (A) Eel Anti-H Precipitin, (B) A. aurantia L-Fucose-Specific Lectin and (C) Rabbit Anti-radish AGP Antiserum.

The surrounding wells in each plate contained, clockwise from the top, $20 \mu \mathrm{l}$ of $0.5 \%$ solution in PBS of the native AGP, $\alpha$-L-arabinofuranosidase-digested AGP, a product of the Smith degradation, none, saline and the carboxyl-reduced AGP. The substances diffused in a moist atmosphere for $24 \mathrm{hr}$ at room temperature.

Table III. Hemagglutination Inhibition Activities of Native AGP AND ITS Modified or Degraded Products

\begin{tabular}{lcc}
\hline & \multicolumn{2}{c}{$\begin{array}{c}\text { Inhibitory activity }(\mu \mathrm{g} / \mathrm{ml}) \\
\text { against }\end{array}$} \\
\cline { 2 - 3 } Sample & $\begin{array}{c}\text { Eel Anti-H } \\
\text { agglutinin }\end{array}$ & $\begin{array}{c}\text { A. aurantia } \\
\text { lectin }\end{array}$ \\
\hline Native AGP & 10 & 40 \\
Carboxyl-reduced AGP & 20 & 160 \\
$\alpha$-L-Arabinosidase-digested & 10 & 80 \\
$\quad$ AGP & & \\
Smith-degraded AGP & 2500 & 1250 \\
$\beta$-D-Glactanase-digested & & \\
products & & 135 \\
$\quad$ Fraction I & 20 & 190 \\
$\quad$ Fraction II & 125 & 5000 \\
$\quad$ Fraction III & 5000 & 500 \\
L-Fucose & 200 & \\
\hline
\end{tabular}

Titer of eel agglutinin or $A$. aurantia lectin was $1: 8$.

Hence, the Smith degradation product lacking L-fucose residues failed to form any precipitin line in response to eel anti-H precipitin and lost the H-like activity as shown in Fig. 1A and Table III, respectively. These serological results agree with the conclusion that the Lfucosyl residues in radish leaf AGPs are essential to the expression of the H-like activity. ${ }^{5}$ ) Further, the formation of sharp precipitin lines in an agar plate and the inhibition of human $\mathrm{O}$ erythrocyte hemagglutination were observed with a rape leaf AGP and its modified products in a reaction with an $A$. auratia L-fucosespecific lectin as shown in Fig. 1B and Table III. This observation strongly supports the hypothesis that the L-fucosyl residues are at the non-reducing terminal end, where they are sufficiently exposed to bind the lectin. In contrast to $\mathrm{H}$-active substances of animal origin, a rape leaf AGP, like radish leaf AGPs, was unreactive with chicken anti-H serum or anti$\mathrm{H}$ lectin from Ulex europeus seeds. ${ }^{3)}$ It is likely that the anti-H antibodies and lectin are highly specific for the terminal L-fucosyl residues as well as the penultimate D-galactosyl residue in mammalian $\mathrm{H}$-active substances, and the ability to discriminate $\alpha$-L-arabinofuranosyl residue. In an immunoprecipitation test with rabbit antiserum raised from the immunization of radish leaf AGPs, the rape AGP had the same immunological response as that of other cruciferous leaf AGPs, yielding a precipitin line fused with the others. The immunological properties of rape leaf AGP toward the antiserum were not affected by chemical and enzymatic modifications as far as examined on an agar plate (Fig. 1C). With the Smith degradation products, a significant difference was found in the immunological response between rape and radish $\mathrm{AGPs},{ }^{5)}$ probably due to the distinct sugar sequences surviving the Smith degradation at the peripheral regions of 
their polysaccharide chains, since they were similar in chemical composition.

Structural studies on rape leaf AGP provided evidence that a major part of the carbohydrate moiety was built up with a core of continuous $\beta$ - $(1 \rightarrow 3)$-linked D-galactosyl residues substituted at O- 6 by side chains of $\beta$ $(1 \rightarrow 6)$-linked D-galactosyl residues. $\alpha$-LArabinofuranosyl residues were present as single or $(1 \rightarrow 2)$-, $(1 \rightarrow 3)$-, and $(1 \rightarrow 5)$-linked units and attached through O-3 to the side chains. Single units of $\alpha$-L-fucopyranosyl and glucuronosyl residues were also located at non-reducing terminal ends. Anomeric configurations of the glycosidic linkages were assigned by the susceptibility to specific glycosidases and serological responses. Interestingly, unlike the presence of two AGP components in radish leaves, only one AGP component was isolated from rape leaf tissues but these AGPs were similar structurally and serologically. Two arabinogalactans (AGs) have been isolated from seeds of Brassica species. ${ }^{14 \sim 16)}$ An AG from B. campestris seeds was apparently distinguished from the AGP of leaf tissues although it was a typical arabino3,6-galactan composed of L-arabinose, Dgalactose, and D-glucuronic acid in a molar ratio of $1: 1.05: 0.13 .{ }^{14,15)}$ Larm et al. working with $B$. napus seeds, have reported the isolation of a high-molecular-weight polysaccharide comprising L-arabinose and Dgalactose in the molar ratio of $10: 1$ but its structural features remained undetermined. ${ }^{16)}$ In view of the distribution of AGPs and AGs in various tissues of cruciferous plants, it would be desirable to investigate their qualitative and quantitative alterations during germination and development by chemical and serological methods to understand the physiological roles of these polysaccharides.

Acknowledgments. We thank Dr. N. Shibuya, National Food Research Institute (Ibaraki), for his gift of Rhodotorula flava $\alpha$-L-arabinofuranosidase and Dr. N. Kochibe, Gunma University (Gunma) for his gift of Aleuria aurantia L-fucose-specific lectin.

\section{REFERENCES}

1) G. F. Springer, Naturwissenschaften, 42, 37 (1955).

2) G. F. Springer, T. Takahashi, P. R. Desai and B. J. Kolecki, Biochemistry, 4, 2099 (1965).

3) K. Nakamura, Y. Tsumuraya, Y. Hashimoto and S. Yamamoto, Agric. Biol. Chem., 48, 753 (1984).

4) Y. Tsumuraya, Y. Hashimoto, S. Yamamoto and N. Shibuya, Carbohydr. Res., 134, 215 (1984).

5) Y. Tsumuraya, K. Nakamura, Y. Hashimoto and S. Yamamoto, Agric. Biol. Chem., 48, 2915 (1984).

6) E. Uesaka, M. Sato, M. Raiju and A. Kaji, $J$. Bacteriol., 133, 1073 (1978).

7) N. Kochibe and K. Frukawa, Biochemistry, 19, 2841 (1980).

8) S. Hakomori, J. Biochem., 55, 205 (1964).

9) I. G. Goldstein, G. W. Hay, B. A. Lewis and F. Smith, Methods Carbohydr. Chem., 5, 361 (1965).

10) R. L. Taylor and H. E. Conrad, Biochemistry, 11, 1383 (1972).

11) F. Downs and W. Pigman, Methods Carbohydr. Chem., 7, 200 (1976).

12) J. S. Garvey, N. E. Cremer and D. H. Sussdorf, "Methods in Immunology. A Laboratory Text for Instruction and Research," 3rd Ed., W. A. Benjamin Inc., Massachusetts, 1977, p. 313.

13) G. O. Aspinall, "Biogenesis of Plant Cell Wall Polysaccharides," ed. by F. A. Loewus, Academic Press, New York, 1973, p. 95.

14) I. R. Siddiqui and P. J. Wood, Carbohydr. Res., 24, 1 (1972).

15) S. C. Churms, A. M. Stephen, and I. R. Siddiqui, Carbohydr. Res., 94, 119 (1981).

16) O. Larm, O. Theander, and P. Aman, Acta Chem. Scand., B29, 1011 (1975). 